\title{
FLaK: Mixing Feminism, Legality and Knowledge
}

\author{
Ruth Fletcher ${ }^{1}$
}

Published online: 17 December 2015

(C) Springer Science+Business Media Dordrecht 2015

\begin{abstract}
This editorial explains the themes of the forthcoming FLaK seminar and how those themes draw on the collective and individual contributions of the articles, interviews and commentaries presented in this issue. At FLaK, we propose to think with others about the kind of 'kitchen table' that FLS might provide into the future. How might feminist legal studies - the approach and the journal-best use its food, equipment, techniques, time, space, mood, energy and commitment? How shall FLS scholars and associates make the most of what we have in a room that can sometimes be confining and confusing, yet also exciting and sustaining? How do others engage with the processes and products of our kitchen table? In considering these issues and more, we propose to draw reflexively on feminist legacies of praxis, internationalism and openness, as we stock up and critically reflect on decolonizing techniques, legal know-how, protest and publishing practices.
\end{abstract}

“When you adopt a 'cookie cutter model' towards violence against women, treating all manifestations as part of the same problem for which only certain remedies apply, it is not enough" (Manjoo and Nadj 2015).

"Our name might have been on the pleadings but it was definitely a collective effort and that feeling of support that we had carried us. Sometimes it felt really scary and lonely to be standing up and bringing this case... We may have lost, but... in terms of highlighting an issue and encouraging activism on it, I think it was worth its weight in gold" (Camplin and Scott 2015).

"Critical social theory today suffers from an overabundance of abstract ideas marketed as recipes that can be used in any intellectual kitchen (to borrow

Ruth Fletcher

r.fletcher@qmul.ac.uk

1 Queen Mary, University of London, London, UK 
Marx's phrase), and so I was all too aware of the risks of having 'chronotopes' be taken up as a new such recipe" (Valverde 2015a).

"Averse to what Valverde calls the superhero model of theorising where great men simply stumble out of bed muttering a world scale theory that promises a god's eye view of the world, she theorises in conversation with other scholars; staking out new theoretical ground without dismissing others, even those she disagrees with" (Kotiswaran 2015).

"Questions of dissent, disagreement and variation in judicial reasoning are often elided in supporting the fiction of a single authoritative 'voice' of that judgment" (Fitz-Gibbon and Maher 2015).

\section{Introduction}

Features of FLS's present-the upcoming 25th anniversary, frustrations with the world of publishing, excitement at new and continuing engagements-have prompted a collective editorial decision to organise 'the FLaK seminar'. ${ }^{1}$ This decision emerged partly in response to the work that is being submitted to FLS. As editors we wanted to pick out certain themes, think about where to go with them, and whether there were interesting gaps to be addressed. Another motivation came from a desire to engage more fully with the expertise and experience of our International Advisory Board members. We started talking about rethinking the relationship between the 'British-and-Irishness' of the Editorial Board and the 'Internationalness' of the Advisory Board drawing on familiar transnational and post-colonial critiques, which do not seem to have permeated the organizing structures and principles of publishing. And then there is the ongoing conversation about how to sustain ourselves as the voluntary academic editors of a feminist legal journal with one metaphorical foot in a corporate research world and the other in a critical feminist imaginary.

For all these reasons, and others that will emerge along the way, FLS Board members invite feminists and feminist-friendly colleagues to gather in London and consider anew the relationship between feminism, legality and knowledge. We are pleased that the Institute for Feminist Legal Studies ${ }^{2}$ at Osgoode Hall Law School, Toronto and the School of Law at Queen Mary, University of London will join us in supporting the seminar, and we look forward to engaging with other expressions of interest in this conversation. This editorial explains the themes of the FLaK seminar and how those themes draw on the collective and individual contributions of the articles, interviews and commentaries presented in this issue. FLS Board members propose to draw reflexively on feminist legacies of praxis, internationalism and openness, as we stock up and critically reflect on decolonizing techniques, legal know-how, protest and publishing practices at the kitchen table.

\footnotetext{
${ }_{1}$ For more information and updates on the FLaK seminar, 30 June-1 July 2016, please see http://www. law.qmul.ac.uk/events/items/167540.html. Accessed 30 November 2015.

${ }^{2}$ For more information about the Institute see: http://ifls.osgoode.yorku.ca. Accessed 30 November 2015.
} 


\section{$F L S$ at the Kitchen Table}

At FLaK, we would like to think with others about the kind of 'kitchen table' that FLS might provide into the future. How might feminist legal studies- the approach and the journal-best use its food, equipment, techniques, time, space, mood, energy and commitment? How shall FLS scholars and associates make the most of what we have in a room that can sometimes be confining and confusing, yet also exciting and sustaining? How do others engage with the processes and products of our kitchen table? Feminist commitment has lived with a critique for some time, a critique that emphasises the unevenness of the legal terrain occupied by feminists with others. One thread of that critical conversation addresses whether FLS should be more explicit in engaging across disciplines and knowledges by opening up the category of 'legality'. FLS has a significant legacy of opening up key categories such as gender and sexuality (Grabham et al. 2009; Hunter and Fletcher 2009), and feminism has long sustained itself by working through a mixture of methods and disciplinary approaches. FLaK aims to build on that conceptual openness and concern for cross-disciplinary approaches as it encourages inquiry into feminist ways of knowing legality (see further Cooper 2014). Does ' $F L S$ at the kitchen table' offer the potential of a methodology for capturing the interactive, multi-perspectival, situated processes of knowing and making legality, without losing an appreciation for the particular vernacular of legal officialdom?

A kitchen-table methodology could be one way of working with legality in more networked or assemblage-like terms (Bhandar 2009), while invoking the legacy of kitchens as important critical sites for feminism and feminist-friendly inquiry, sites which could be DIY or professional, home or away. As governance seems to push for ever more academic compartmentalisation, does it help critical inquiry to approach legality as a combination of routine, unexpected and creative practices that are repurposed over and over again in connection with others? Kitchen-table legal methods could become one way of responding to Valverde's call for critical sociolegal studies to work through a Bakhtinian concern for chronotopes, a call that is considered by four commentaries in this issue (Valverde 2015a; Kotiswaran 2015; Harrington 2015; Roele 2015).

Valverde's commentary provides "a situated intellectual history" of Chronotopes of Law (2015b) as she discusses the motivations behind her decision to pursue a critique of the "space race in theory" literature. Her frustration with the way in which time and space were being decoupled, and space asserted in abstract terms as a priority for guiding critical inquiry, led her to reconsider Bakhtin's work on chronotopes. The chronotope is not a philosophical method of synthesizing time and space, and certainly not a conceptual flag for marking out territory and rallying troops, but "a useful technique for generating analyses of how particular temporalities are linked to particular modes of spatialization in ways that show regularities but no "determinations in the last instance'." Kotiswaran quotes Valverde's original text: "Time as it were, thickens, takes on flesh, becomes artistically visible; likewise, space becomes charged and responsive to the movements of time, plot, and history" (2015b, 9-10). But more importantly 
perhaps for FLaK, Bakhtin's dialogism, with its emphasis on the dialogical and unfinished meaning of texts, presents "a powerful resource for generating analyses of legal processes that highlight law's embodiedness and materiality, including its various, often unpredictable, spatiotemporal dynamics" (Valverde 2015a)

In her commentary Kotiswaran takes up Valverde's analysis as it emphasizes "the need for moving away from metaphysical notions of 'space' and/or 'time' and to explore more fully the intertwined relationship between temporalisation and spatialization in our study of governance" (2015). It is precisely Valverde's understanding of theory as a pragmatically oriented assemblage of ideas, which can be put to work, that Kotiswaran sees as offering "a rich and multidimensional view of legal regimes in dynamic operation with each other." Moreover Kotiswaran draws out how Valverde's theoretical approach reflects "a feminist desire for praxis where the theory/case study distinction is demolished and we work towards what she calls a pragmatics of legality."

Harrington responds to Valverde's call for engagement with dialogism and chronotopical analysis by emphasizing the rhetorical dimensions of claims and counterclaims for jurisdiction in British medical law (2015). He accepts that chronotopes are plural, overlapping and sometimes contradictory, but argues that patterns become more apparent with a scalar shift 'down' to the level of particular disciplines within law. By way of illustration he shows how the shift from the Bolam $^{3}$ doctor-defined standard in the context of pre-treatment information disclosure, towards the Montgomery ${ }^{4}$ standard of the reasonable patient, was accompanied by a revisioning of the clinical encounter in British medical law. The availability of information on the internet and the sense in which treatment is driven by bureaucratically organized teams rather than individual medical 'craftsmen' made the Bolam standard implausible and facilitated change.

Like Kotiswaran and Harrington, Roele emphasizes the open-endedness of Valverde's approach to legality. She notes how Valverde does not use Bakhtinian concepts as "building blocks in an Escherian architecture," but instead works a "set of loosely connected concepts and insights" in order to "shed new light on how acts of communication take place" (2015). Roele is particularly interested in Valverde's approach to jurisdiction as the governance of legal governance through time, space and mood. This is partly because the terrain of public international law rarely takes jurisdiction for granted and is thus a great site for testing whether chronotopical analysis adds something new to the socio-legal toolkit. Roele finds that the chronotope reveals aspects of UN Security Council (UNSC) practice that usually remain on the peripheries of international lawyers' vision. For example, the preambular paragraphs of UNSC Resolutions fix the time and space of each resolution in the moment of its creation through the use of the continuous present tense. For Roele these aspects of jurisdiction games shed light on how the UK was able to make a plausible case for the legality of the invasion of Iraq. In brief, the continuous present of Resolution 1441 in 2002 "recalling all its previous

\footnotetext{
3 Bolam v Friern Hospital Management Committee [1957] 1 WLR 582

${ }^{4}$ Montgomery v Lanarkshire Health Board [2015] UKSC 11
} 
resolutions" made it possible to overlook the 12 years hiatus between it and the 1990 resolution's authorisation of the use of force.

FLaK promises to continue the dialogue that Chronotopes engages by approaching legality at the kitchen table, a spacetime that is laden with a mix of emotional and financial investments. The meaning and significance of kitchen tables rest in part on their embeddedness ${ }^{5}$ in the building as a whole, on their role in providing a site for preparing and eating food, while being open to being used in other ways: for conversation, play, homework. Some kitchen tables work slowly and deliberately. Others are sites of frantic and fast mess. Still others are characterized by their refusals to conform. The kitchen table—so much more than empirical object and felt experience-will provide $F L S$ with an opportunity to reflect on the elements that make up legality and the chronotopical movement between those elements.

\section{Stocking Up with Decolonizing Techniques}

As we think about the limits and potential of a kitchen table approach, this seminar will focus in particular on processes of stocking up as we consider decolonizing techniques of knowledge. Decolonizing perspectives offer a lot to 'FLS at the kitchen table' precisely because they have developed extensive expertise in making themselves heard on their own terms while speaking to pluralities and universalisms (e.g. Keenan 2014). ${ }^{6}$ Stocking up with decolonizing perspectives aims to take full advantage of what Kotiswaran calls the "international desire for a thriving sociolegal paradigm of anti-formalist legal scholarship" that is evident in South Asia, South East Asia and Latin America at the same time "as socio-legal scholars in North American schools are beginning to question the parochial contexts of their own theorising of the law" (2015). As she goes on to say, bringing the postcolonial home to Western law and problematising its understanding as 'the monolith of modernity' "has become even more crucial as conventional narratives of progress and the difference of postcolonial 'others' are reiterated every single day whether in relation to debates over the refugee crisis, modern slavery, climate change or food security."

Tamale's article, published by FLS in 2008 and currently available open access as an Editors' Choice, ${ }^{7}$ is a notable example of this commitment from an African context (2008). She argues against a mainstream opposition of culture and rights and for a recuperation of the ways in which African culture "promotes and develops women's rights." Cornell and van Marle (2005) have provided another inspiring

\footnotetext{
5 For examples of critical socio-legal thinking on the 'embeddedness' of law within socio-economic interactions see further Ashiagbor et al. (2013) and Lange et al. (2015).

${ }^{6}$ For an argument that the feminist project is impeded by failures to integrate critique of the impact of colonialism and racism, see Ruparelia (2014).

7 See Editors' Choice Articles at http://www.springer.com/law/international/journal/10691?detailsPage= societies for three different articles, which are made available free to download for a 2 months period. Accessed 30 November 2015.
} 
example as they consider the particular ways in which Ubuntu ${ }^{8}$ could be legally justiciable, and address the necessity of thinking of the new South African Constitution as an archive in order to understand how legal thought 'comes to be'.? With the FLaK seminar, we intend to draw on these kinds of approaches in order to question some of the ways in which legality is being invoked, ${ }^{10}$ and run with questions and themes already raised by FLS contributors (e.g. Dimova et al. 2015; Stewart 2011).

In this issue, Cao's analysis of glorious motherhood, as enacted through Chinese abortion law and policy, could be understood as contributing to this thread of kitchen-table conversation (2015). Cao's article contextualizes the particular ways in which Chinese reproductive policy carves out motherhood as a glorious pathway for women, even as it differentiates itself from the many other legal regimes which have recognized legal subjectivity of the foetus in some way. She tackles a legality that is often seen as profoundly particular in its tolerance of abortion, provides insights in how that legality has 'come to be', and draws out points of connectiondiscriminatory reproductive regulation and nationally inflected glorification of kinds of motherhood-that speak to legalities from other locations.

\section{Doing Legal Know-How}

FLaK intends to pick up another thread of current conversations in feminist legal studies by thinking about legal know-how as an object that is made through feminist critical engagement. Feminists have a long and inventive history of finding, generating and adapting legal know-how. Women's centres and LGBT phonelines, among others, became expert at translating information about life and law in ways that were responsive to everyday experiences of issues from housing to violence (e.g. Southhall Black Sisters 1990). These processes of taking hold of information, deploying it to improve life, while keeping an eye out for translational potential, have something to tell us about successes and failures in making law listen. They also provide key examples of governance which is "dynamic, multi-vocal and interactive" (Kotiswaran 2015).

Feminist judgments and women's court projects have engaged legal imaginations across a wide range of topics and jurisdictions, as they ask how feminist knowledge

\footnotetext{
${ }^{8}$ See section 5 of Cornell and van Marle's article for discussion of "Ubuntu behind the law," in which they say: "Ubuntu in a profound sense, and whatever else it may be, implies an interactive ethic, or an ontic orientation in which who and how we can be as human beings is always being shaped in our interaction with each other."

9 They say: "We more than understand the risk of essentialising Africa. But we believe that the only cure for this risk is through the kind of re-evaluation through anthropology and genealogy that Mudimbe calls for. Otherwise we simply fall back into formulations that carry within them the worst aspect of the colonial project: the full-scale trivialising of the traditional mode of life and the spiritual framework of the African Weltanschauungen, and denial of the gnosis through which we struggle to articulate and interpret its meaning."

${ }^{10}$ Valverde comments in this issue "I have a particular antipathy to the assumption (built into many debates about theoretical matters) that the more of the world one's account claims to encompass, the more prestige one has as an intellectual" (Valverde 2015a).
} 
might be translated into the language of official legality (Enright et al. 2016; Hunter et al. 2010; Women's Court of Canada 2006, Feenan 2009, Douglas et al. 2015). In this issue, Fitz-Gibbon and Maher (2015) and McLoughlin (2015) consider, in different ways, some of the lessons learned through these projects. ${ }^{11}$ 'Donning uncomfortable robes' draws out the significance of feminist discomfort with formal legal engagement; a discomfort which is also articulated by Manjoo as she talks about not being sure that she wanted the position of UN Special Rapporteur (Manjoo and Nadj 2015). Drawing on Butler's work on intelligibility, iterability and the communality of violence and vulnerability, Fitz-Gibbon and Maher argue that feminist judgments necessarily require some uncomfortable compromises with unjust gendered institutions. As they analyse the process of producing a feminist judgment in an Australian intimate homicide case, $R v$ Middendorp, ${ }^{12}$ they argue that a feminist re-articulation of the law's carceral power can have the effect of unsettling gendered oppression, even if it does not challenge institutional power. McLoughlin's analysis of 'maiden judgments' identifies the limits of the gender representation argument on the actual working of law. She analyses the judgments delivered by three women judges on their first sitting in the Australian High court, judgments with which their colleagues on the bench concur in a gesture of welcome. She questions the extent to which the woman judge can ever shake-off her status as the maiden bound to conform for the sake of comity. In a sense, FLaK aims to build on the way that feminist judgments have opened up thinking about processes of translating feminist knowledge into formal legality, and the limits thereof, but will shift the focus away from judges and courts towards other sites of legal intervention (see further Sircar 2012).

The interview with Emma Scott, Director of RoW, provides another insight into these kinds of knowing legal practices (Camplin and Scott 2015). RoW is a charity that provides legal advice and information for women in England and Wales, by women solicitors and barristers. They started out 40 years ago with the intention of acting on the fifth demand of the Women's Liberation Movement and fighting for the legal and financial independence for women. As Scott explains, the advice line has always been a central aspect of RoW, "telling the stories of women's experience of the law, and the gaps and the barriers that women were facing in terms of access to justice." In 2014, RoW brought a judicial review that challenged the reduced provisions for family law legal aid available for victims of domestic violence as a result of the Legal Aid, Sentencing and Punishment of Offenders Act 2012. ${ }^{13}$ In particular, they challenged the necessity of requiring prescribed forms of evidence, usually legal proceedings or police or medical involvement, to 'prove' domestic violence, and the necessity of a 2-year time limit for evidence. On the formal legal point they lost in the High Court, on the basis that the Regulations reflected Parliament's intention, but are appealing the decision.

\footnotetext{
11 For a related consideration of the connection between judicial independence and diversity on the bench, and some of the research questions generated thereby, see Lawrence (2010).

12 (2010) VSC 202 (19 May 2010).

${ }^{13} R$ (On the Application of Rights of Women) $v$ The Lord Chancellor and Secretary of State for Justice (2015) EWHC 35 (Admin).
} 
But, as the interview clarifies, the significance of this legal process goes beyond the court's decision, important though that is. Through the process of bringing the judicial review they acted on their own research that $40 \%$ of women could not produce the required evidence in spite of living with domestic violence. They obtained support from the Law Society in the form of an indemnity, which shielded them from the financial risk of having to pay their own and the Secretary of State's costs. They had a conditional fee arrangement with their solicitors, the Public Law Project, and were part of a wider network of legal and women's organisations campaigning against the cuts to legal aid, which Scott says gave them a feeling of support that carried them through. Even thought they lost the case at first instance Mrs Justice Lang did say that they had proved that women were being stopped from accessing legal aid because of the evidence criteria, a judicial aside which could be used in future advocacy. But more importantly the case was worth its "weight in gold" because of the value of raising awareness, the media attention and the "fantastic" amount of support RoW received from other organisations and individuals.

In a similar vein, Manjoo discusses the significance of participation in civil society organizations and university law clinics for the generation of knowledge about the impact of violence on women's participation and autonomy in public and private spaces (Manjoo and Nadj 2015). This had a number of outcomes. It led to an intellectual questioning of what liberation actually means for women, including in post-conflict settings. But it also led to "numerous activities including providing free legal services to women victims of violence; participating in the drafting of legislation in the area of domestic violence; the setting up of a domestic violence intervention unit in a court (the first ever in South Africa); and providing educative services to communities on human rights." Work at a national and local level also fed and influenced work at the international level both through participation in global civil society such as the Women's Caucus for Gender Justice, “a wonderful feminist organisation that honoured and reinforced the importance of linking local knowledge to global initiatives, when shaping the discourse on women's human rights." Advocacy on international legal instruments, such as the Maputo Protocol and the Rome Treaty, sought to "shape thinking about remedies and victims rights in an international court context, including through engendering evidentiary rules and rules of procedures" and considered "how to translate manifestations of violence against women into categories of crime."

RoW's deployment of legal know-how through the judicial review and Manjoo's articulation of the links between experiencing and criticizing violence and the generation of educational, law reform and service provision activities, indicate the timeliness of further analysis of movements between and across legalities. Such know-how activities present an opportunity better to understand "the fluid process by which such utterances are taken up, read or misread or ignored in subsequent interactions" (Valverde 2015a). Feminist legal studies has rich traditions of criticizing legal method and doing interdisciplinary work on the mobilization of legal and non-legal norms, ${ }^{14}$ but there is more to be learned about the particularities

\footnotetext{
14 For one example of a feminist consideration of how cultural information is incompletely collected and imperfectly understood in courtrooms and legal processes see Lawrence 2001.
} 
of how legal information gets translated and taken up. This is partly because the boundaries between all these different elements of know-how-information, advice, research, listening ears and resonant voices - thicken and thin out in tension with legal aid cuts and non-provision, professional and research governance, and promotion of voluntarism and civic activism. And yet activists, students, women's groups, trade unions, pro-bono professionals, clinics and advice-centres continue to find ways of providing know-how and supporting engagement with legal processes as people remake their lives. It seems there is a lot to learn from all kinds of creative and routine deployments of legal knowledge.

\section{Enacting Dissent}

As many of the contributions in this issue touch upon, protest and dissent are significant activities by which feminists, with others, have mobilized knowledge of law's effects towards its critique and change. Marches, hunger strikes, knickerbombing, graffiti, slow handclaps and even silence have been among the many techniques used to register disagreement with legal conditions. These different forms of protest invite us to consider not only the spacetime which generates the urge to step out and turn the legal gaze back on itself, but also the knowing ways in which protests name legal problems and suggest solutions. For Manjoo, experiences of state-sponsored violence against women in detention, of participating in student protest marches, and of being arrested and assaulted were all formative in the shaping of legal consciousness (2015). Overtly feminist forms of protestslutwalks, chaddi campaigns, SistersUncut, SpeakingofImelda-draw attention to protest's diverse forms of self-differentiation and adaptation. ${ }^{15}$ Protest makes use of legal knowledge and intervenes into legal relations in the same moment that it pulls away from legal capture. Policing of protest generates particular challenges for critical engagement as spaces are closed down and brutalizing power extinguishes life (see further El-Enany 2015).

The contributions to this issue illustrate significant feminist expertise in the movement between the spacetimes of protest at law, and the spacetimes of professionalized advice within it. Manjoo is explicit in discussing how her experience of anti-apartheid protesting was formative for her (2015). Valverde mentions her own history of doing feminism and the ways in which intellectual and activist work "used to be" seen as deeply entwined (2015a). Sometimes this movement is narrated as if it was a chronological transition of progress from protest to legitimate use of legal power as the politics of inclusion exercises its force. But it is clear that the history is often not so linear, and that inclusion is not always the objective. Indeed the spaces of legal advice-giving may generate movement into protest. In considering different processes, performances and genres of protest, we

\footnotetext{
15 On slutwalks and chaddi campaigns see Kapur 2012. On Sisters Uncut's recent protest on violence against women at the premier of Suffragette in London, see Kwei 2015. On Speaking of IMELDA's protest actions see Speaking of IMELDA (2015) and Enright (2014).
} 
hope to think more about how different moments-boiling, ${ }^{16}$ simmering, steaming - of protest work knowledge through and against legality.

\section{Getting the Word Out}

'Getting the word out' motivates all kinds of publishing activities as we strive to communicate ideas, findings, reflections and even hunches. FLS, in common with many academic journals, publishes a mix of original articles, interviews, commentaries and book reviews, accessible largely via institutional subscription with some limited open access content. We aim for diversity in content so as to reflect the different stages of academic knowledge production as writers share their reading, document their exchanges, and provide considered analyses. Feminism has long recognized that some of the deepest learning happens on the street, or in the kitchen, rather than in the university. At the same time, academia, including academic journals, provides an important set of tools and spaces for making the most of that learning. ${ }^{17}$

As colleagues and friends experiment with open access media, how should FLS, as an established subscription-based journal, best maintain and develop existing knowledge-distribution networks while encouraging engagement with the ' $F L S$ collection' and the rapid on-site responses of social media? In considering this, we would like to open our kitchen-table up to insights about archival and curatorial practices, experimental and alternative publishing, sustainability within corporate and university structures, feminist engagements with copyright, critical editing practices and creative dissemination in the age of social media. Do join us-in person at FLaK, via @FLS_journal, or by submitting your work_as we reconsider what it means to know and do feminist legal studies.

\section{References}

Ashiagbor, Diamond, Prabha Kotiswaran, and Amanda Perry-Kessaris (eds.). 2013. Towards an economic sociology of law. Oxford: Wiley-Blackwell.

Bhandar, Brenna. 2009. Constituting practices and things: The concept of the network and studies in law, gender and sexuality. Feminist Legal Studies 17(3): 325-332. doi:10.1007/s10691-009-9128-3.

Camplin, Hannah, and Emma Scott. 2015. "We are a group of feminist lawyers doing what we can": An interview with Emma Scott, Director of Rights of Women. Feminist Legal Studies. doi:10.1007/ s10691-015-9299-z.

Cao, Weiwei. 2015. Exploring 'glorious motherhood' in Chinese abortion law and policy. Feminist Legal Studies. doi:10.1007/s10691-015-9291-7.

\footnotetext{
16 Interestingly, in this issue, Valverde mentions that part of the situated history of Chronotopes of law was her reaction to Harvey's use of space: "Well my blood just boiled," see further 2015b 37-43.

17 The Inspirational Women of Law exhibition is one imaginative example of a collaboration between Law and Fine Art. It culminated in a photographic exhibition of a number of women who have used law to make a significant contribution to society, under the direction of Nikki Godden-Rasul and Kathryn Hollingsworth; see http://www.iwlaw.uk. Accessed 30 November 2015.
} 
Cooper, Davina. 2014. Everyday utopias: The conceptual life of promising spaces. Durham: Duke University Press.

Cornell, Drucilla, and Karin van Marle. 2005. Exploring ubuntu: Tentative reflections. African Human Rights Law Review 5(2): 190-225. http://www.ahrlj.up.ac.za/cornell-d-van-marle-k Accessed 1 Nov 2015.

Dimova, Margarita, Carrie Hough, Kerry Kyaa, and Ambreen Manji. 2015. Intimacy and inequality: Local care chains and paid childcare in Kenya. Feminist Legal Studies 23(2): 167-179. doi:10.1007/ s10691-015-9284-6.

Douglas, Heather, Francesca Bartlett, Trish Luker, and Rosemary Hunter (eds.). 2015. Righting and rewriting law. Oxford: Hart.

El-Enany, Nadine. 2015. Ferguson and the politics of policing radical protest. Law and Critique 26(1): 3-6. doi:10.1007/s10978-015-9151-2.

Enright, Máiréad. 2014. Sparing Enda's Blushes: Speaking of IMELDA and \#knickersforchoice. Human Rights in Ireland. http://humanrights.ie/constitution-of-ireland/sparing-endas-blushes-speaking-ofimelda-and-knickersforchoice/. Accessed 30 Nov 2015.

Enright, Máiréad, Julie McCandless, and Aoife O'Donoghue (eds.). 2016. Judges' troubles and the gendered politics of identity. Oxford: Hart (forthcoming).

Feenan, Dermot (ed.). 2009. Women and judging. Feminist Legal Studies 17(1): 1-99.

Fitz-Gibbon, Kate, and JaneMaree Maher. 2015. Feminist challenges to the constraints of law: Donning uncomfortable robes? Feminist Legal Studies. doi:10.1007/s10691-015-9292-6.

Grabham, Emily, Davina Cooper, Didi Herman, and Jane Krishnadas (eds.). 2009. Intersectionality and beyond: Law, power and the politics of location. Abingdon: Routledge-Cavendish.

Harrington, John. 2015. Time and space in medical law: Building on Valverde's chronotopes of law. Feminist Legal Studies. doi:10.1007/s10691-015-9295-3.

Hunter, Rosemary, Claire McGlynn, and Erika Rackley (eds.). 2010. Feminist judgments: From theory to practice. Oxford: Hart.

Hunter, Rosemary, and Ruth Fletcher. 2009. Law, gender and sexuality: The making of a field. Feminist Legal Studies 17(2): 289-332. doi:10.1007/s10691-009-9133-6.

Kapur, Ratna. 2012. Pink chaddis and Slutwalk Couture: The postcolonial politics of feminism lite. Feminist Legal Studies 20(1): 1-20. doi:10.1007/s10691-012-9193-x.

Keenan, Sarah. 2014. Moments of decolonization: Indigenous Australia in the here and now. Canadian Journal of Law and Society 29(2): 163-180.

Kwei, Sarah. 2015. Why I protested with Sisters Uncut at the Suffragette Premiere. The Independent. http://www.independent.co.uk/voices/why-i-protested-with-sisters-uncut-at-the-premiere-ofsuffragette-a6685686.html. Accessed 30 Nov 2015.

Kotiswaran, Prabha. 2015. Valverde's chronotopes of law: Reflections on an Agenda for socio-legal studies. Feminist Legal Studies. doi:10.1007/s10691-015-9300-x.

Lange, Bettina, Fiona Haines, and Dania Thomas (eds.). 2015. Regulatory transformations: Rethinking economy-Society interactions. Oxford: Hart.

Lawrence, Sonia. 2010. Reflections: On judicial diversity and judicial independence. In Judicial Independence in Context ed. A Dodek and Lorne Sossin. Irwin Law 193-216.

Lawrence, Sonia. 2001. Cultural (in)sensitivity: The dangers of a simplistic approach to culture in the classroom. Canadian Journal of Women and the Law 13: 107-122.

Manjoo, Rashida, and Daniela Nadj. 2015. 'Bridging the divide': An interview with Professor Rashida Manjoo UN Special Rapporteur on Violence against Women. Feminist Legal Studies. doi:10.1007/ s10691-015-9303-7.

McLoughlin, Kcasey. 2015. A particular disappointment? Judging women and the high court of Australia. Feminist Legal Studies. doi:10.1007/s10691-015-9301-9.

Ruparelia, Rakhi. 2014. Legal feminism and the post-racism fantasy. Canadian Journal of Women and the Law 26(1): 81-115. doi:10.3138/cjwl.26.1.81.

Roele, Isobel. 2015. Reading UN security resolutions through Valverde's chronotopes. Feminist Legal Studies. doi:10.1007/s10691-015-9293-5.

Sircar, Oishik. 2012. Spectacles of emancipation: Reading rights differently in India's legal discourse. Osgoode Hall Law Journal 49(3): 527-573. Online at: http://digitalcommons.osgoode.yorku.ca/ohlj/ vol49/iss3/4/. Accessed 30 Nov 2015.

Southall Black Sisters. 1990. Against the grain: A celebration of survival and struggle, southall black sisters 1979-1989. London: Southall Black Sisters. 
Speaking of I.M.E.L.D.A. 2015. Dirty work still to be done: Retrieving and activating feminist acts of resistance. Contemporary Theatre Review. http://www.contemporarytheatrereview.org/2015/ margaretta-darcy/ Accessed 30 Nov 2015.

Stewart, Ann. 2011. Gender, law and justice in a global market. Cambridge: Cambridge University Press.

Tamale, Sylvia. 2008. The right to culture and the culture of rights: A critical perspective on women's sexual rights in Africa. Feminist Legal Studies 16(1): 47-69. doi:10.1007/s10691-007-9078-6.

Valverde, Mariana. 2015a. On chronotopes of law. Feminist Legal Studies. doi:10.1007/s10691-0159296-2.

Valverde, Mariana. 2015b. Chronotopes of law: Jurisdiction, scale and governance. Abingdon and New York: Routledge.

Women's Court of Canada. 2006. Canadian journal of women and the law 18(1). http://www.thecourt.ca/ decisions-of-the-womens-court-of-canada/ Accessed 30 Nov 2015. 